\title{
'The Migratory Bird' Pension App : A New Era of Travel Endowment Through Internet Across The Taiwan Straits Will Be Opened
}

\author{
Li Quanlin ${ }^{\mathrm{a}, *}$, Huang Xianyang ${ }^{\mathrm{b}}$ \\ Collaborative Innovation Center for Peaceful Development of Cross-Strait Relations, College of \\ Liberal Arts of Fujian Normal University; Fuzhou, Fujian China, 350007 \\ aliquanlin@126.com,b421832882@qq.com
}

Keywords: 'Internet plus'; 'Migration birds pension'; 'Travel pension'; Both sides of Taiwan Strait; Service platform management

Abstract: Nowadays in china, with the increasing trend of 'aging society', the state has begun to introduce policies to encourage social forces to run the pension industry. The arrival of the information age has promoted the widespread adoption of smart phones. Under the time background, the main direction of 'the migratory bird' pension app is providing Internet old-age service platform and broking service for old-age institutions and elderly people in the process of 'the migratory bird' pension. This APP has functions such as information consultation on old-age health care, tracking location, safety navigation, environmental early warning, one-button dialing and so on, which based on two tools: 'the Internet platform' and 'The migratory bird' endowment. This has not only satisfied the growing demand for pension services in the country, but also the new old-age pension model under the Internet era. The application of the migratory bird type pension APP on both sides of the Taiwan straits will enable the elderly population of China to enjoy the high-quality old-age service in Taiwan, and also benefit the introduction of mainland China's talents for the elderly in that. Moreover, China's vast pension service market will bring huge economic benefits to Taiwan.

\section{Introduction}

\subsection{The Arrival of 'Aging Society'}

At present, China is not only the most populous country in the world, but also one of the countries with the fastest aging population .Moreover, by the middle of this century, according to the United Nations, the number of people in China over 60 will reach 500 million, which will surpass the total number of people in the United States. The main feature of China's aging population is its rapid growth and its size. By the end of 2014, China had 21.2 million people over the age of 60, accounting for 15.5 percent of the total population, according to the national bureau of statistics. By 2050, China's elderly population is expected to reach 480 million, almost a quarter of the world's 2.02 billion people [1]. Due to the expansion of the size of the elderly population, the market size and 
demand of the old age industry show exponential growth.

\subsection{National Policies Encourage Social Forces to Run the Pension Industry}

Pension service is a service which jointly completed by government and commercial institution, The reasonable situation is social forces, commercial force apply for the construction of pension industry, which bases on the guarantee of government. The huge market demand and huge gap between supply and demand make the pension industry a "sunrise industry" with great potential for development. The national policies also require "sunset" business that service hundreds of millions of old people into a thriving sunrise industry, which become the important force in making it the adjustable structure, livelihood, and promoting the upgrade.

In recent years, adjusting to the aging of our country, the country has introduced a series of policies to encourage social forces to run the pension industry. "a number of opinions of the state council on encouraging and guiding the healthy development of private investment” in 2012 (new 36 Guidelines), task of deepening reform and speed up the development of pension services put forward by the state council executive meeting on August 16, 2013, "the several opinions of state council on accelerating the development of pension services” (No 35 Document in 2013 of the State Council ), The guidance of the state council general office on promoting the combination of health and pension service (No 84 Document transmitted in 2015 of the State Council general office) and so on, many policies from the state council policy made it clear that the "leading role" in construction of pension industry is social power, which exert the principal role of social forces should be on the basis of the government revealing all the details.

The implementation opinion of the ministry of civil affairs on encouraging and guiding private capital to enter the realm of pension service "( [2012] no.105) made it clear that supporting the private capital into the endowment industry, and provides a number of preferential measures and financial support on encouraging the private capital to enter the realm of pension service. In 2014, the ministry of finance, national development and reform commission, the ministry of civil affairs, the national aging "The notice about completing the work for the government to buy endowment service notice ([2014] no.105) put forward that by 2020, establish comparatively perfect system of government purchase endowment service, this also encourage the development of social forces to provide for the aged in the government level.

In order to further innovation of financial products and services, and promote the speed up the development of pension services, support structural reform of the supply side, people's bank of China 、 the ministry of civil affairs、 the CBRC、 the CSRC jointly issued " The guidance on speeding up the development of financial support pension service industry " ([2016] no. 65) in March 2016, which make it clear to " the improvement and innovation of financial services, increase financial support, widely mobilize social capital to participate in, increase social pension reserve of wealth, increase the ability to pay pension service, ensure the smooth implementation " a sense of security " strategic goals.”Speeding up the decision deployment of pension services' development, meeting society's growing multi-level and diversified demand of financial services in the field of pension as a starting point, improving the efficiency of financial resource allocation on pension services as the direction, overall planning all kinds of financial resources, promoting reform and innovation continuously, establishing and perfecting endowment service industry to speed up the development of financial organizations, products, services and policy system, to improve and enhance the level of pension financial services field."'By 2025, basically built wide coverage, various perfectly, fully functional, efficient, safe and healthy financial service system which adapted to our country population aging process, and meeting the requirements of the well-off society." Contents include: (1) encouraging Banks to lend to small and micro pension service enterprises;(2) encouraging eligible 
pension service enterprises to raise funds through listing and issuing bonds;(3) supporting local PPP mode construction or development of pension institutions;(4) carrying out the pilot of individual tax deferred business pension insurance;(5) continuing to carry forward the pilot of elderly people's housing reverse mortgage insurance;(6) encouraging the form of innovative professional financial organization and exploring the establishment of pension banking system;(7) striving to meet the needs of China's population aging process and meet the requirements of a well-off society by 2025 .

\subsection{The Large-Scalle Application of Smart Phones}

On the other hand, the arrival of the information age has promoted the widespread adoption of smart phones. Because smart phones have the advantages of simplicity and convenience, a growing number of older people have learned to use touch-screen smart phones. According to a survey made by a team at the Great Golden Lake Aged-care Center of Sanming city in November 2015, there are 62 among 100 old people can be independent use smart phones and 17 can learn to use our development independently service platform app after team members simply guide of research[2].The proportion of old man who be able to learn and use smart phones independently is as high as $89 \%$, which proves that the old people have strong learning ability, and extensive social basis of our project.

\section{Research and Development Direction and Main Business}

\subsection{Research and Development Direction}

The main direction of this project is to provide Internet service platform and broking service for old-age institutions and elderly people. This includes many cross-domain services, such as publicity services, sales services, product services, information services, public service, etc. Therefore, my project needs to develop business in many aspects, mainly including the following:

(1) the marketing team needs to follow the market information closely, and do not lose the strength to develop marketing strategies to seize the best market.

(2) the research and development team needs to develop a more valuable pension service based on project operation, and extract valuable information from domestic and foreign mature cases.

(3) information teams need to get all kinds of market information in a timely manner and be prepared to avoid risks while doing all kinds of information services.

(4) the public welfare team should run the public welfare business of the project to strive for more public welfare funds. That would put a lot of money into the services of unbred elderly.

\subsection{Main Business-Introduction and Function Interpretation of Pension APP}

\subsubsection{Advisory digest function}

This feature is designed to three pieces, provide for the old man lives worldwide consulting, global big news selection, areas such as new events, makes every effort to meet the information needs of older people to a great extent.

\subsubsection{A key dial-up}

A key dialing function improves the service experience of the nursing home and simplifies the management cost of staff. Because the function can meet the needs of two groups of people: a. the nursing home staff dial-up to call the elderly in the nursing home B. Elderly people can dial in contact with the staff and family members of the nursing home. In addition, in times of crisis, only the 
elderly can click the first aid button, the background will automatically transfer the signal to the elderly family's phone number and 120 who will arrive and take first aid measures at the first time.

\subsubsection{The record axis of old man's big event}

This feature in a time sequence to complete record the major events that took place in the process of pension, such as the name of the diseased time and disease, this from the old registration login our platform and registered members. This record axis is recorded by the staff of the pension institution and then updated on the original timeline. This feature can reduce the information statistics caused by the frequent changes of elderly residents in the hostel and provide more detailed pension services for the elderly. In addition, the children of old people can learn about their parents and improve their service experience through the time axis.

\subsubsection{The function of nursing home pushing the information}

The staff of the nursing home can choose to push the information to the elderly or elderly family members, which can simplify the work greatly. For example, one day the old man went on a group trip and had been scheduled to gather at 17:30, but the weather changed and it was going to rain. At this point, our staff can use our platform APP to directly push the phone to each old person's mobile phone, and set the return journey in advance. If the nursing home can push the information to the family members of the old people, they will tell the old people what activities they have arranged next week, which can increase the trust of the elderly family members.

\subsubsection{Information display of nursing homes (functions of the mall)}

Through this function, the elderly or their families can select and view the nursing home that provides the "migratory bird" pension, the environment of the hardware environment, the medical services, the contact information, etc.

\subsubsection{Registered function}

Through registration function we can distinguish between three groups of users who are the elderly nursing user group, the home family user group and the elderly user groups .The different personalized function be provided respectively for different user groups, such as family members will see their old man's location when using positioning function.

\subsubsection{Details of the elderly person's personal information}

The details of the old man's personal information will enable us to provide more detailed services. After registration, the old man should fill out a series of detailed information, such as his previous medical history, special care needs, and the level of the nursing home.

\subsubsection{Environmental warning function}

The main feature of this feature is automatic alerts. Together with the local weather geological environment, we upload medical information and medical records of the elderly to the Internet. Once the elderly are in areas or areas where the weather is extreme, our software will automatically alert them and their families by sending SMS messages.

\subsubsection{The function of review and feedback}

Through our APP, the elderly and their families can use the online registration function to provide 
requirements and requirements. We will give the elderly the details of the retirement plan in a week.

To sum up, we set up a bridge for the promotion and business smoothly, reduce the distance of communicating with customer, reduce the cost of enterprise management, improve the service quality, and will digitalize part of the endowment behavior digital successfully through the above 11 function.

\section{Product Strategy and Marketing Strategy.}

\subsection{Product Strategy}

\subsubsection{Product Positioning}

The main business of our team is to provide services for "migrating birds" through the Internet platform, which can serve both the agency and elderly consumers. The project will undertake the work of "migration birds" pension for the elderly and assist the elderly to sign the pension agreement with the pension fund. When the rights and interests of the elderly are infringed, they can help the elderly to obtain proper solutions. The project aims to connect with the national pension alliance to connect the north and south pension institutions. Thus, as a bridge between the elderly and the old-age institutions, the perfect way for the elderly to create "wait-and-bird pension".

\subsubsection{Phase Marketing Strategy of Product Life Cycle}

The start-up phase (first to third year): this project adopts rapid penetration strategy. Because at this stage most of the customers are still impressed by the old-age institutions .For this, the project will focus on public welfare, i.e. not charging any fees to improve customer experience. The purpose of these strategies is to pre-empt them and bring the fastest market penetration and market share to enterprises .In addition, using the service quality advantage to attract customers in the market, in order to bring the fastest rate of return.

Development phase (4 to 5 years): At this stage, the core of this project's marketing strategy is to extend the product's growth and service coverage as much as possible. We will improve the functions of the APP and improve the quality of service according to customer demand and other information of the market. Because consumers already have a certain understanding of 'migratory birds' pension service, the project's performance is growing rapidly .Although this project has a better understanding of the process of engagement with national pension institutions, the market competition is fierce because of a large number of competitors .In addition, we have added new sales channels to further increase market share and enhance publicity to establish a strong brand image.

Stable stage ( 5 years later): this project adopts the product improvement strategy to improve the characteristics of the 'migratory bird' pension service .Because at this time the market is basically saturated, product sale is stable. In this regard, the project is more reflected in the public welfare of the service of "migratory birds" .Our targeted upgrade measures include: enhancing the customization effect of the service, collecting and integrating user experience data and requirements.

\subsection{The Overall Marketing Strategy of The Project}

Quality service is the core of this project, and "Internet platform" and "migratory bird pension" are the two main sources and tools of project marketing. In addition, the characteristics of enterprises are light assets, big data and cloud computing, which spread the concept of caring, exclusive and integrated services. The project will build a comprehensive marketing system and accurately grasp the consumption trend to adapt to market changes and take into account the common long-term interests of enterprises, consumers and markets. The project is oriented to the online consumer 
demand of the elderly, and combines the public welfare, promotion, brand culture publicity, advertising and other factors.

The company will set up a number of professional marketing teams to be responsible for the training and operation of the whole team. The marketing team seeks out target customers by tapping into the Internet pension market through links with governments and pension agencies. The team will also conduct a large number of public relations activities to enhance project awareness and enhance communication and interaction with customers to disseminate project culture and introduce project service projects. As the consumer market matures, the project will enhance public awareness and assume social responsibility to set up charitable foundations for vulnerable people.

\subsection{Product Marketing Plan: Medium and High-End Pension Service and Customer Training Platform}

\subsubsection{Middle - and High-End Pension Service}

The core business of the all-in-one service platform of 'Internet plus migratory birds' is to provide online integration of 'migratory bird type old-age' service for the elderly. We will compete on differentiation, which will take a focus on the high-end market, organic combination of low-end market, and strategic abandon of the low-end market .We will use the new type of 'migration birds' pension to make up for the neglect of traditional pension institutions. In the end, we rely on 'Internet + pension' to provide a private, high-end old-age care service for the elderly.

\subsubsection{Customer Training Platform}

The project always adheres to the tenet of public welfare. The main customer source of the project is the middle and high-end consumer group, but they are not the main source of profit for the project. The main source of profit for the project is a certain introduction and promotion fee to the pension fund, while the elderly are completely free. When the project grows to a certain size, it will dock with the government and pension institutions, offering discounts or free pension plans for the elderly. In addition, the project will set up pension funds to enhance customer loyalty and enhance brand image.

\subsubsection{Interpretation of Trademarks}

The team logo is above, the logo is composed of the middle pattern and the text below. The main body pattern is a circular, meaning "round heaven and square earth". Two elderly people on crutches are in the circle. A bird with an old man wrapped in its mouth on their head. The old man went from the north of fallen leaves on the right to the south of the blooming oak tree on the left, meaning "migration birds" endowment. The underfoot of the old man is a land composed of wireless networks, which means "Internet plus migratory bird" service platform. The following text is the name of our platform.

\subsubsection{Brand Marketing Expectations}

The brand is the soul of the enterprise, running through all the business activities of the whole enterprise. The brand target is formulate the specific, quantitative strategic direction for the enterprise, which made by the brand manager according to the enterprise management direction. The consumer's identity to the enterprise brand, including "enterprise's service - enterprise culture". The brand positioning of our project is to provide the elderly with humanized, convenient and diversified pension contents, which will eventually form a well-known brand in the domestic "migration birds" pension. 
The initial stage (1-3 years): this project will be supported by government departments and rely on publicity tools such as APP and website .It is a highly differentiated core value in the market to reflect the purpose of this project, that is to design unique "migratory bird" pension plan for every elderly person .Integration and quality services will make a good impression on the real and potential customers at the beginning of the project's entry into the market.

Development phase (4-5 years): this project has basically completed the docking with the qualified "migratory birds" pension institution or large-scale tourism project in Fujian province. The project will gradually take the target customer group from Fujian to China, and strive to achieve certain popularity in the famous cities in the provinces. In addition to the promotion and promotion of enterprise brands, the project will also adopt more diversified forms of publicity. In order to reflect the public welfare nature of the project, the project will conduct a series of public lecture activities.

Stable stage (5 years): To be a famous domestic "migration birds" endowment integration services project, which gathers pension service mediation, establish public welfare fund, national endowment display platform, and other functions. To refine the core value of the brand, fully consider the prospective and the capacity of the brand, and pre-bury the pipeline of brand extension to maximize the brand value. With the concept of "migration birds" deeply rooted in the hearts of the people, the "migration birds" pension has become a way of life for the elderly.

\section{4. 'The Migratory Bird' Pension App: a New Era of Travel Endowment through Internet across the Taiwan Straits will be Opened}

\section{1. 'Internet + Migratory Bird Pension': a New Pension Model that Meets the Market Demand}

By the end of 2015, the proportion of China's population aged 65 years accounted for $10.5 \%$ of the total population, surpassing the world average. According to "The report of 2015-2020 China pension industry development prospects and of investment tactical analysis 'released by forward-looking industry institute, China's 60 years of age has more than 220 million, accounting for $15.5 \%$ of the total population in 2014. Experts predict that China will in a "super-aging" society from 2020.By 2053, China's elderly will reach 487 million .In other words, one in three people is an old man. However, there is a shortage of nursing homes, which can only accommodate 3 percent of the elderly in our country.

For the urgent demand of construct pension industry in China, making social force to be the leading part of construct needed by the government to guide. What' more, policies in guiding social forces took to the stage of the construction of the pension industry also Intensive introduced in recent years. In the future, we need to clarify the relationship between government and market, make social forces become the main force of the construction of pension industry. In recent years, China's pension industry will have explosive growth. The huge economic benefits of the pension industry are attracting domestic and international investors. Endowment is breakthrough of the ole pattern traditional family such as endowment patterns, forming Coexisting situation of Family, community, market pension appeared different pension. The appearing of new patterns such as A long-distance endowment house for pension, "migratory birds" and ecological endowment to integrate blazing a road of socialization and marketization with the international experience. The pension industry has the characteristics of long industrial chain and wide range, and has a driving effect on the upstream and downstream industries. "Migratory birds" endowment is a kind of brand-new pension mode which can make the elderly change their own endowment with the seasons change like migratory birds. It can be said to be a "Migratory birds" tourism more than "Migratory birds" endowment for using China's north and the geographic differences to find the most suitable endowment environment.

Since the 21st century, China has entered the information age rapidly. The exponential 
development of the Internet industry has forced the traditional industry to make the transition in a short time. In order to join the elderly and pension agency, our " migratory birds" endowment project cater to the present "Internet +" trend, using the Internet technology to build "information bridge" among endowment institutions and the old. This project exactly focus on this new type of old-age pension and unlimited market prospect to create an integrated service platform app of "waiting for the old-age ".We can develop a new APP service terminal to record the old man's health in detail according to the needs of elderly. This service terminal can cooperate with China endowment chain alliance below the line. And then, it can provide a good place to pension and make appropriate service system for the old man.

\subsection{The Chinese Mainland and Taiwan Have Complementary Advantages}

"Taiwan entered the elderly society in 1993 according to the refine of the United Nations.The elderly population reached 2.7 million, which account for 11.53 percent of the total population at the end of 2014. Taipei city went into the senile society with the 65-year-old people account for more than $14 \%$ of the total population in October 2014. What's more, the development trend is more and more serious, the elderly will accounts for $29 \%$ of the total population in 2025.The proportion of young adults burdening elderly population is 3.4 young burden an old man [3]. Taiwan will become the region which aging index is highest in the world by 2033."Taiwan's basic pension policies and regulations are: the old people's welfare act, the decade plan of long-term care, the protection law for people with disabilities, and 'the act of long-term care and service'." [3]. "Taiwan pension service facilities.1. Nursing institution: elderly people who are in good health and can live by themselves;2. Maintenance institutions: elderly people who are in need of self-governing ability and unskilled care services; 3. Long-term care facilities: provide some health care services for the elderly with chronic diseases; 4 . Dementia care facility: elderly people who have operational capacity but need to be taken care of for moderate dementia;5. Nursing home: providing 24 hours of personal and nursing care, and rehabilitation training and medical services; 6 . Hospice care organization: providing hospice care for the elderly in need.” [3].

"Taiwan attaches great importance to the standardization and specialization of old-age care services as well as the establishment of a unified pension service standard .Endowment institutions and health care is a health body, the pension service standards we know include: "the old man welfare orientation checklist", "maintenance (long-term care) standard contract template", "establish a plan of community care", " tracking service preparation of care service in examining the old man ", etc. Taiwan realize the specialization of endowment service team by regulating endowment professional team of doctors, pharmacists, nurses, care, social work, counseling, rehabilitation division, dietitian, chef, maintenance personnel, financial personnel, administrative personnel, lawyers and other professional and technical personnel and so on. Specific standards for technical personnel in each industry are specified." [3].

Taiwan focuses on home and community care services, "Taiwan's endowment task has specific goals: the core of service they offer for the old man is " extension of the health status and shorten the phase of the disability, the elderly quality aging with health and dignity ".To achieve this goal, Taiwan has established the national pension system and long-term care insurance system, for citizens and their family members to get the necessary basic life safeguard and care services in the elderly and disabled. Taiwan focuses on home and community care services, the family service and community service are subdivided, Home-based services including: home services, home care, auxiliary equipment purchase, and occupy the barrier-free facilities to improve services, nutrition catering service for the elderly, emergency rescue; Community services include day care, community rehabilitation, elderly nutrition and catering services[3]. 
With the deepening of economic and cultural exchanges between the two sides of the straits, the elderly population of the mainland can enjoy the results of standardized and specialized construction of Taiwan's old-age care services through the "migratory bird " pension service platform. They can not only access Taiwan's professional pension institutions and medical institutions, but also enjoy high-quality services provided by professional pension teams. At the same time, the professional talents of Taiwan will spread the advanced old-age service concept and experience to the mainland, and go to the front line of China's old-age service construction. Finally, the large-scale application of the Internet pension service platform will provide a huge market for the old-age service in Taiwan, which will bring great economic benefits.

\section{Acknowledgements}

This paper is supported by the National-sponsored Social Sciences Funding Program of China (the project approval number is 12BZW104); National Natural Science Foundation of China (NSFC, the project approval number is 41571142); Supported by Program for New Century Excellent Talents in Fujian Province University (NCETFJ, and the project approval number is JA13078S).

\section{References}

[1]China Report Hall, (2015), Analysis on the Future of the Pension Industry in 2015: Huge Business Opportunities, Beijing.

[2] Li, Q.L. (2016) The Alliance of Migratory Birds' Old-age Service Companies - Explore the Exploration of National Innovative Sojourn Pension Model. Beijing: Student Entrepreneurship and Innovation Training Program.

[3] Wang, J.W. (2016) The Inspection Report of Taiwan Endowment Service. Shandong Province Government. 